\title{
El nacimiento de Orión en Euforión de Calcis y en Ovidio: estudio de los orígenes y la tradición de un mito beocio*
}

\author{
Joan Pagès Cebrián \\ Universitat Autònoma de Barcelona \\ Joan.Pages.Cebrian@uab.cat \\ The birth of Orion in Euphorion of Chalcis and Ovid:
study of the origins and tradition of a Boeotian myth
}

Ovidio (Fast. V 493-544) nos ofrece el testimonio de una versión del nacimiento de Orión que se remonta, por lo menos, a Euforión de Calcis. Dicha versión es irreconciliable con las tradiciones panhelénicas transmitidas por la épica arcaica. En el artículo se analiza el relato a partir del texto de Ovidio y del escolio de la Ilíada que nos ha transmitido la versión de Euforión. Desde una perspectiva estructural, el relato contiene motivos de carácter ritual que pueden relacionarse con un rito de fertilidad anatolio testimoniado en un texto hitita, el denominado Ritual contra la impotencia de Paškuwatti (CTH 406). El sustrato cultual compartido por las dos riberas egeas, la europea y la asiática, sugiere la pervivencia de motivos de origen ritual transfigurados en mitemas integrantes del relato analizado.

Palabras clave: Euforión de Calcis; Ovidio; Fastos; Orión; Hirieo; Mitografía.
Ovid (Fast. V 493-544) narrates the birth of Orion in according to a particular version that goes back at least to Euphorion of Chalcis. This version is incompatible with the archaic conception of Orion's birth in epics. The article discusses the story from Ovid's text and from the scholium of the Iliad which contains Euphorion's version. From a structural perspective, the story contains ritual motifs that may relate to a fertility rite attested in a Hittite text, the so-called Paškuwatti's ritual against sexual impotence (CTH 406). The cultic substratum shared by both, European and Asiatic, Aegean banks, suggests the survival of certain features of ritual origin transfigured into some of the mythemes of the story discussed.

Key words: Euphorion of Chalcis; Ovid; Fasti; Orion; Hyrieus; Mythography.

* Estudio realizado en el marco del Proyecto BFF2010-16301 del Ministerio de Ciencia e Innovación. Este artículo parte de mi contribución al Coloquio Internacional Euphorion et les Mythes: images et fragments, realizado en la École Normale Supérieure de Lyon el 19 y 20 de enero de 2012. En dicha contribución, dedicada a los testimonios de Euforión transmitidos por los escolios menores a la Ilíada, se analizaba el uso de motivos relacionados con gigantes. En uno de sus apartados, el que trataba de Orión (véase Pagès Cebrián 2013, pp. 257-262), se hallan, de forma embrionaria, algunas de las ideas desarrolladas en el presente artículo. 
Ovidio, en un pasaje de los Fastos, relata el peregrino nacimiento de Orión en Beocia $^{1}$. Su fuente directa parece haber sido una referencia al mito en alguna obra de Euforión de Calcis ${ }^{2}$ cuyo texto se ha perdido, pero que conocemos gracias a un escolio mitográfico a la Ilíada $a^{3}$ que cita a dicho autor como fuente. El relato coincide en gran medida con Ovidio:

'Y

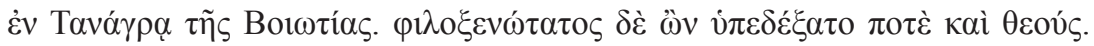

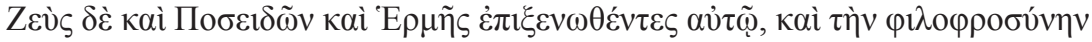

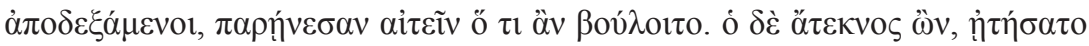

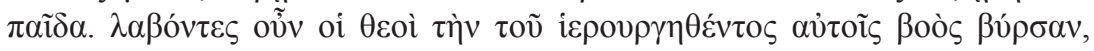

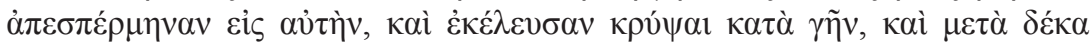

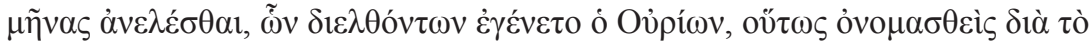

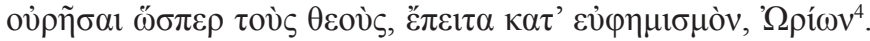

Hirieo, hijo de Posidón y Alcínoe, una de las hijas de Atlante, vivía en Tanagra de Beocia. Era tan hospitalario que llegó a acoger incluso a dioses. En

${ }^{1}$ Ou., Fast. V 493-544. Dada la extensión del fragmento me abstengo de transcribirlo completo. Para suplir esta carencia facilito un resumen: Orión, según esta versión, era hijo putativo de Hirieo, campesino beocio que ofreció hospitalidad a Júpiter, Mercurio y Neptuno en su humilde cabaña. En el momento de la epifanía, es decir, al advertir Hirieo que estaba dando cobijo a los dioses mismos, éstos le conceden el cumplimiento de un deseo. Hirieo, que era viudo y había jurado fidelidad perpetua a su esposa en su lecho de muerte, pidió un hijo. Los dioses practicaron un extraño ritual, que Ovidio omite por pudor pero que conocemos por el escolio y otras referencias que analizaremos a continuación. Dicho ritual consistía en orinar sobre la piel del buey de labranza que el campesino había sacrificado para ofrecer un banquete a los tres dioses, único animal de que disponía. A continuación le ordenaron enterrar la piel mojada con la orina y aguardar los nueve meses de gestación. Transcurrido este tiempo, Hirieo desenterró la piel y de ésta nació Orión. Véase Massa-Pairault 2013, p. 49.

${ }^{2}$ Fr. 127 De Cuenca, 105 van Groningen, 130 Clua, 65 Lightfood, 132 Acosta-Hughes/Cusset.

3 Sch. D a Il. XVIII 486 Van Thiel, texto sin duda tributario del Mythographus Homericus (Montanari 1995 passim; Van Rossum - Steenbeek 1998, cap. 3; Cameron 2004, cap. 3; Higbie 2007, pp. 250-251). El mismo texto se recoge en la colección de Incredibilia de Paléfato, fragmento 51, penúltimo del corpus, tal vez copiado textualmente del Mitógrafo Homérico y añadido en el epítome que conservamos.

${ }^{4}$ El escolio mitográfico es más largo; se narra en él también la muerte de Orión y su catasterismo. Omito esta parte para centrarme en el tema y no extender demasiado la cita textual. Téngase en cuenta, sin embargo, que el texto acaba refiriéndose a Euforión explícita-

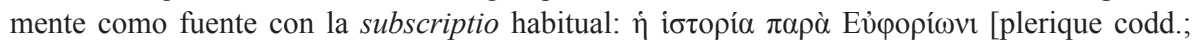

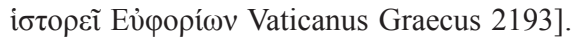


efecto, Zeus, Posidón y Hermes se hospedaron en su casa y, en reconocimiento a su bondad, le exhortaron a que pidiera lo que quisiese. Él, que no tenía descendencia, pidió un hijo. Entonces los dioses, cogiendo la piel del buey que había sido sacrificado en su honor, eyacularon en ella y le ordenaron enterrarla y desenterrarla al cabo de diez meses, transcurridos los cuales nació Urión, así llamado porque era como si los dioses hubiesen orinado ${ }^{5}$; más tarde, por eufemismo, Orión.

Si damos crédito al testimonio de Estrabón ${ }^{6}$, es posible que Píndaro ya hubiese atribuido la paternidad de Orión a Hirieo: ő $\pi$ ov (sc. 'Y pía) ò 'Y pıv̀̀

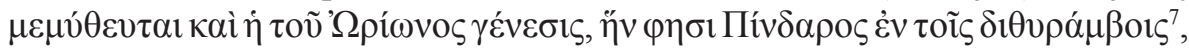
«(en Hiria), donde se narra la historia de Hirieo y el nacimiento de Orión, al que se refiere Píndaro en sus ditirambos». La cita es muy imprecisa y de ella no se desprende necesariamente que Píndaro hubiese narrado el mismo relato. Lamentablemente, pues, no podemos restituir los detalles de la versión pindárica, por lo que es imposible saber hasta qué punto Euforión y, posteriormente, Ovidio, se basan en el poeta beocio. No es muy verosímil, por otra parte, que Píndaro hubiese relatado tal historia, dado su escepticismo por cuanto se refiere a tradiciones que degradan a los dioses y a su interés por el imaginario panhelénico en detrimento de las peculiaridades locales. La noticia de Estrabón parece sugerir simplemente que Píndaro se hubiese referido al nacimiento de Orión en Hiria, sin más.

Las características del relato que leemos en Ovidio y en el fragmento euforioneo sugieren la posibilidad de que Euforión haya recuperado una tradición oral que no parece haber dejado huella en la literatura arcaica, ya que, como veremos, entra en contradicción con la tradición más divulgada, la difundida por la poesía homérica y hesiódica. La importancia de las tradiciones orales ha sido puesta de manifiesto por R. Thomas ${ }^{8}$, quien afirma que el

${ }^{5}$ El problema de la fluctuación en el uso de los verbos para «eyacular» y «orinar» se abordará infra.

${ }^{6}$ Str. IX 2.12 = Pi., Fr. 73 Snell-Maehler.

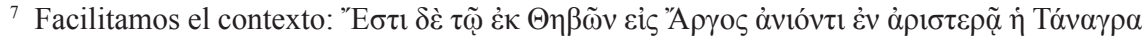

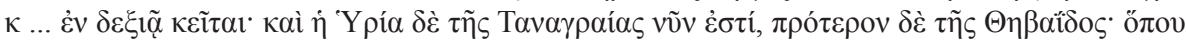
ó 'Y

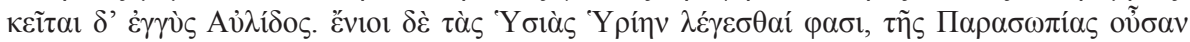

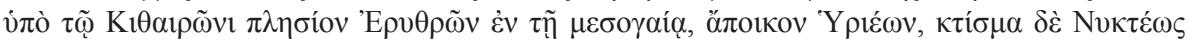

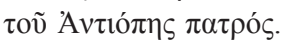

8 1992, pp. 105, 108-113. 
mecanismo que las hace aflorar en un momento determinado y la manera como son reinterpretadas y puestas en circulación responde a factores culturales, sociales, políticos e ideológicos.

Ninguna fuente arcaica conservada considera a Orión hijo de Hirieo. En Homero', Orión es meramente una constelación, con la excepción del pasaje de la nekyia, en el que aparece como un gigante cazador a quien Odiseo ve en el Hades ${ }^{10}$. La filiación hesiódica no está clara. Según Eratóstenes ${ }^{11}$, seguido por Higino, Hesíodo consideraba a Orión hijo de Posidón y de Euríale, hija de Minos, mientras que Germánico en los escolios a Arato afirma que el relato de la piel mojada con la orina de los dioses y enterrada se hallaba ya en el poeta de Ascra (cf. Fr. 148 Merkelbach-West). Las dos noticias se contradicen, por lo que no disponemos de suficientes datos para discernir cuál era realmente la filiación que Hesíodo daba para Orión. En toda la tradición directa conservada de este poeta Orión sólo aparece como constelación ${ }^{12}$. Por otra parte, si la fuente última del extraño relato fuese Hesíodo, ¿por qué el escoliasta/mitógrafo cita a Euforión, una fuente posterior? Más bien parece que el testimonio de Germánico sea de dudosa fiabilidad o, al menos, debemos leerlo críticamente. Como fuente principal cita a Aristómaco y simplemente añade al final similem originem refert Hesiodus. Aristómaco es un autor del que no sabemos prácticamente nada, sólo que escribió sobre agricultura y que es citado varias veces por Plinio ${ }^{13}$.

Sea como fuere, el relato del nacimiento de Orión de la tierra no parece haber penetrado en la corriente de la épica panhelénica, pues difícilmente sería compatible con la filiación supuestamente hesiódica, la que lo hace hijo de Posidón y Euríale, hija de Minos.

Detectamos, pues, dos tradiciones diversas sobre el nacimiento de Orión, como ya advirtió el redactor de la Biblioteca atribuida a Apolodoro ${ }^{14}$, la del

9 Il. XVIII 488-490, XXII 29; Od. V 121, 274.

${ }_{10}$ Od. XI 310, 572.

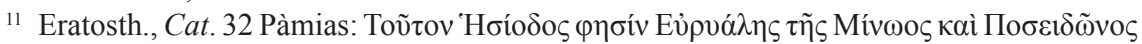
Eĩval; cf. Hyg., Astr. 2.34: Hunc Hesiodus Neptuni filium dicit ex Euryale Minois filia natum; v. comentario de Pàmias (p. 206, n. 286).

12 Op. 698, 609, 615, 619.

13 Nat. XIII 47, XIV 24, XIX 26.

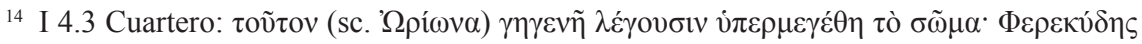

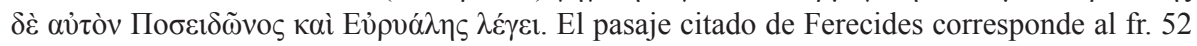
Fowler; v. comentario de Cuartero (p. 109, n. 86); Fontenrose 1981, pp. 18-19. 
héroe, que parte de Hesíodo y es seguida por Ferecides y Eratóstenes, y la del gigante nacido de la tierra, la cual, según el testimonio de Estrabón, podría haber partido de Píndaro, quien recogió una tradición beocia difícil de analizar dada la falta de testimonios escritos al tratarse de una tradición de transmisión oral. Esta última es la que hallamos en Euforión y Ovidio, así como en Germánico, quien cita a Aristómaco.

En el ámbito beocio existe una tercera tradición, conocida de forma deficiente, gracias a un fragmento de Corina ${ }^{15}$. La poetisa de Tanagra establece un vínculo entre Orión e Hirieo que no parece ser de filiación. La trama narrativa del fragmento, al menos a partir de lo que podemos leer con una mínima continuidad en los restos del papiro, no coincide con el relato de Euforión y Ovidio. No hay duda, pues, de que nos hallamos ante dos tradiciones beocias sobre el mismo personaje: la primera, la de Euforión y Ovidio, que nos presenta a Orión como hijo de la tierra; la segunda, la de Corina, que, a pesar de algunas coincidencias que pasaremos a analizar, discrepa notablemente ${ }^{16}$. La poetisa beocia nos habla de nueve hijas del río Asopo ${ }^{17}$. Dichas doncellas se unieron a cuatro dioses olímpicos; tres a Zeus, tres a Posidón, dos a Apolo y una a Hermes (versos $\left.12-18^{18}\right)$ :

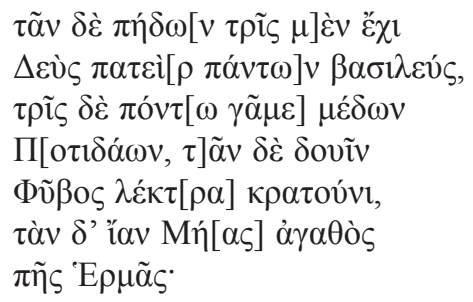

${ }^{15}$ PMG 654 (PBerol. 284. col. iii). No entraremos a discutir aquí sobre la datación de Corina. Remitimos a Page 1953, Guillon 1958, Clayman 1993. Cf. también Palumbo-Straca 1993, quien nos da un resumen del status quaestionis y nos advierte de la distancia ideológica y literaria que separa a la poetisa de su (suponemos) contemporáneo Píndaro; éste, poeta coral de ámbito panhelénico, compone en la lengua doria, una Kunstsprache lírica alejada de su dialecto natal; aquélla, poetisa local en dialecto beocio; v. también Ortolá-Guixot 2005, Collins 2006, pp. 19-20.

${ }^{16}$ En cuanto a la disparidad de tradiciones etiológicas locales v. Parker 2011, p. 27.

${ }_{17}$ Ya desde la editio princeps de Wilamowitz (Berliner Klassikertexte V 2, pp. 49-52); v. Bowra 1938; Guillon 1958, pp. 50-51; Larson 2001, pp. 39-41; Larson 2002, pp. 50-56; Gentili 2003; Collins 2006, pp. 24-26.

${ }_{18}$ Para la edición, interpretación y comentario del pasaje completo v. Page 1953, pp. 22-27. 
... y de tus hijas, a tres las posee Zeus padre, rey de todo, a tres las desposó el señor del mar, Posidón, de los lechos de otras dos Apolo es dueño, con la que queda se unió Hermes, el excelente hijo de Maya, ${ }^{19}$

Nótese el hecho de que, de los cuatro dioses, tres son los que gozaron de la hospitalidad de Hirieo en el relato de Ovidio/Euforión, a saber, Zeus, Posidón y Hermes. Existe otro testimonio tardío del mismo relato en los escolios de Licofrón ${ }^{20}$, en el cual el tercer dios no es Hermes sino Apolo. Licofrón, poeta también de Calcis, una generación anterior a Euforión, se refiere a Orión mediante el apelativo $\tau \rho i ́ \pi \alpha \tau \rho o \zeta$; así pues, conocía también esta tradición ${ }^{21}$.

Como fruto de esas uniones ${ }^{22}$ nació una generación de profetas, cincuenta en total (22-31):

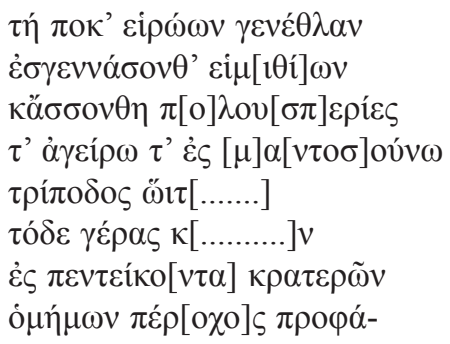

19 La traducción de los pasajes transcritos de Corina es la de F. Rodríguez Adrados (Lírica Griega Arcaica, Madrid 1980, pp. 435-436).

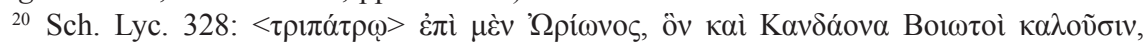

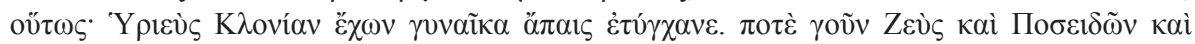
А A

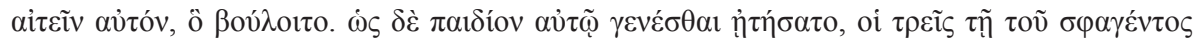

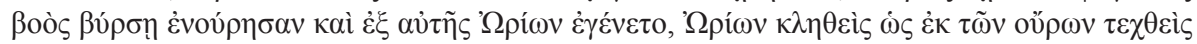

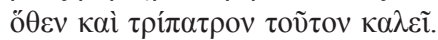

${ }^{21}$ De hecho, Euforión tan solo alude de forma muy oscura, casi críptica, a Orión, en la

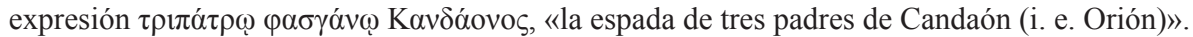
La hipálage complica aún más el sentido, así como el uso del nombre Candaón para referirse a Orión. De hecho, no es Licofrón quien transmite el mito, sino su escoliasta interpretando la oscura alusión del poeta. En el caso de Euforión, es posible que sucediera lo mismo: el poeta aludía enigmáticamente al mito, y un escoliasta, recurriendo a la tradición exegética mitográfica, ofrecía un resumen (v. infra). Los escolios de Euforión no se han conservado, pero es posible que el mitógrafo homérico los hubiese consultado y, citando a Euforión, está citando no sólo el texto del poeta sino también sus escolios.

${ }^{22}$ El motivo del adivino beocio nacido de una ninfa nos recuerda la filiación de Tiresias, hijo de la ninfa Cariclo. 
$\tau \alpha \varsigma \sigma \varepsilon \mu \nu \tilde{\omega} v[\alpha \dot{\delta} \delta] v ́ \tau \omega \nu \lambda \alpha \chi \omega ̀ v$

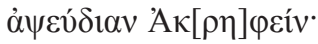

...ellas andando el tiempo engendrarán un linaje de semidiosas y serán fecundas y carentes de vejez de acuerdo con el trípode oracular... ese privilegio lo poseo de entre cincuenta fuertes hermanos (sólo yo), el excelso poeta Acrefén que obtuve en suerte la infalibilidad del recinto sagrado...

Uno de estos cincuenta vates fue Hirieo, hijo de Posidón ${ }^{23}$, que tomó posesión del oráculo, expulsando a Evónimo, quien a su vez lo había recibido de Apolo mismo (32-37):

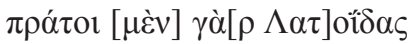

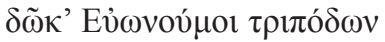

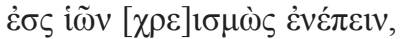

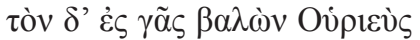
$\tau \mu \mu \grave{\alpha}[v] \delta \varepsilon v \dot{\tau \varepsilon \rho o \varsigma}$ ไ̌ $\sigma \varepsilon \varepsilon$,

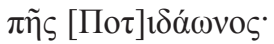

... pues el hijo de Leto concedió a Evónimo el primero decir profecías desde sus trípodes; luego Hirieo le expulsó del país y obtuvo el segundo ese honor, el hijo de Posidón;

Después de Hirieo, Orión hereda el oráculo (37-41):
ह̌兀 $\pi 1-$

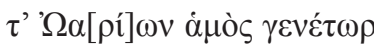
$\gamma \tilde{\eta} \alpha[v F] \alpha ̀ v ~ \alpha ̉ \pi \pi \alpha \sigma \alpha ́ \mu \varepsilon v o \zeta$

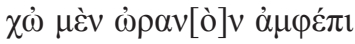

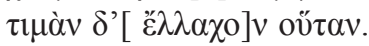

más tarde Orión, mi padre, cuando se hizo dueño de la tierra de aquel. Ahora él mora en el cielo y yo (obtuve) el honor.

La forma $\alpha \dot{\pi} \pi \alpha \sigma \alpha ́ \mu \varepsilon v o \varsigma$ es, según el diccionario de $L S J$, equivalente beocio de $\alpha \dot{v} \alpha \kappa \tau \eta \sigma \alpha ́ \mu \varepsilon v o \varsigma$, «habiendo recuperado». De acuerdo con lo dicho anteriormente, Orión recuperó como profeta una tierra de la que era legítimo heredero, que había pertenecido a Evónimo, quien había sido expulsado de

${ }^{23}$ Según la versión más divulgada, hijo de la pléyade Alcínoe. 
ésta por Hirieo. Si tal interpretación es correcta, es muy improbable que Hirieo hubiera sido padre de Orión. Más bien parece que el texto se esté refiriendo a un oráculo vinculado a una tierra concreta. Wilamowitz identificó dicho oráculo con el de Apolo en el monte Ptoion, cerca de Acrefia ${ }^{24}$. Para

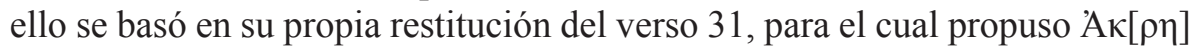
peív, «Acrefén», supuestamente héroe epónimo local y persona loquens en el texto de Corina. Pero dicha restitución es problemática. El antropónimo

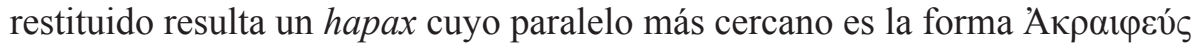
testimoniado por Esteban de Bizancio ${ }^{25}$. De hecho, ya Wilamowitz manifestó sus reservas, así como Lobel (1953) y Guillon $(1958)^{26}$, quien no admite siquiera que el texto de Corina se refiera al oráculo de Apolo Ptoios. La restitución textual alternativa de Lobel seguida por Guillon es $\alpha \dot{\alpha}[\rho \eta] \varphi<v>$ cív, forma beocia equivalente a la ática $\dot{\alpha} \kappa \rho \alpha \iota \varphi v \tilde{\eta}$, en acusativo, en concordancia

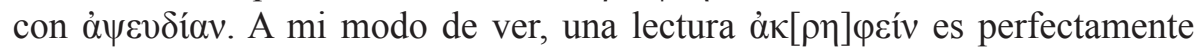

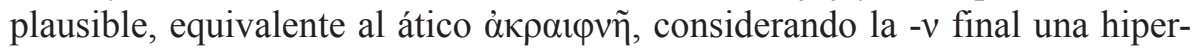

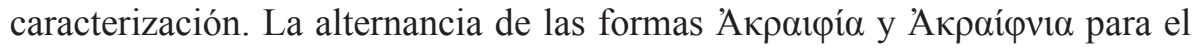
nombre de la ciudad ${ }^{27}$ puede explicar también un doblete creado en sentido inverso para el adjetivo parónimo; abona esta hipótesis la forma $\sin v$ del

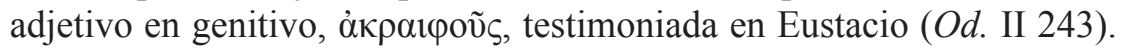

Schachter (n. 26) advierte que, aun admitiendo tal restitución, el texto podría perfectamente referirse al oráculo de Apolo Ptoios. Incluso se puede considerar el uso del adjetivo restituido como un juego de palabras que evoca necesariamente el nombre de la localidad, Acrefia.

Sea como fuere, no hay base suficiente para identificar el oráculo al que se refiere Corina con el de Apolo Ptoios ${ }^{28}$. La geografía desaconseja admitir esta hipótesis. La proximidad del río Asopo a la localidad denominada Hiria

24 Frazer 1898, pp. 97-104; Shachter 1982, pp. 52, 63.

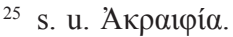

26 V. Schachter 1981, p. 62.

27 El doblete se da también en el gentilicio, como testimonia Éforo ( $F G H 70 \mathrm{~F} 229$ )

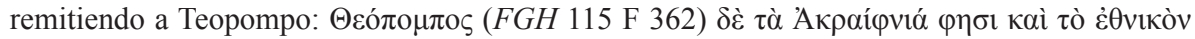

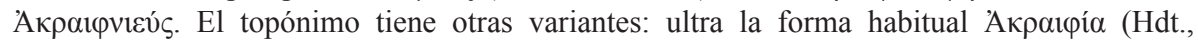

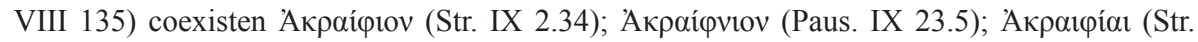
IX 2.27); v. Frazer 1898, p. 97 ss.

28 La arqueología ha identificado el oráculo de Ptoion con el yacimiento de Lycovrisi (Ducat citado por Schachter 1981, p. 52). Guillon 1958, pp. 50, 54-55, argumenta también en contra de dicha localización. 
('Ypía) es fundamental para la identificación del lugar. Acrefia queda bastante alejada del cauce del Asopo, hacia el norte. Hiria sin duda se hallaba en la

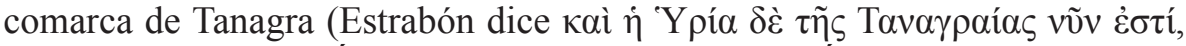
v. nota 7), cercana a Áulide. Los topónimos Hiria y Áulide aparecen citados conjuntamente en el Catálogo de las $\mathrm{Naves}^{29}$, por lo que deducimos que debían de hallarse cercanas. El río Asopo, al menos en su cauce actual, desemboca unos kilómetros más al sur. Estudios topográficos y arqueológicos llevados a cabo durante los años 60 del siglo pasado identificaron Hiria con los restos encontrados en la colina llamada en griego moderno Tseloneri, Glypha o Glikha ${ }^{30}$. Según Estrabón (cit.) Hiria estaba ya deshabitada en su época, e

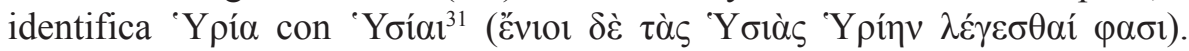
Pausanias $^{32}$ habla de las ruinas de un santuario de Apolo en un lugar llamado también 'Yoíal, donde los sacerdotes vaticinaban bebiendo agua del pozo sagrado. Schachter 1981, p. 49 no da crédito al testimonio de Pausanias, pero advierte sobre el hecho de que la adivinación por ingestión de agua es habitual en Beocia. ¿Debemos identificar, con Estrabón ${ }^{33}$, Hysiae con Hiria? De hecho, a pesar de que existe suficiente base lingüística (vid. infra), las fuentes delatan una confusión considerable ${ }^{34}$. En cualquier caso, Hiria, lugar de

${ }^{29}$ En su forma jónica 'Ypín, Il. II 496.

${ }^{30}$ Cf. Fossey 1988. Los restos de cerámica hallados dan testimonio de habitación ininterrumpida desde el neolítico hasta época romana, datos que coinciden con el testimonio de Estrabón. No nos constan nuevas prospecciones al respecto. Para la información más reciente, que no aporta nada nuevo respecto a los estudios de Fossey, v. Funke 2013.

${ }^{31}$ Cf. E., Antiope fr. 28 Kambitsis (Fr. 180 Kannicht).

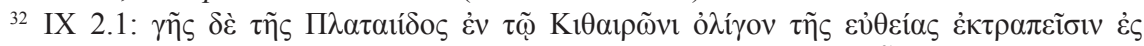
$\delta \varepsilon \xi i \grave{\alpha}$ Y Y

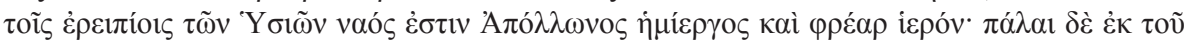

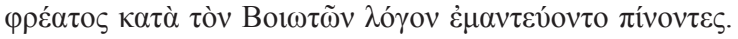

${ }^{33} \mathrm{~V}$. nota 7.

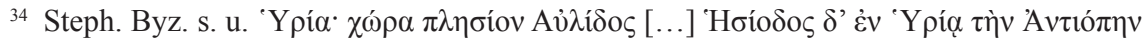

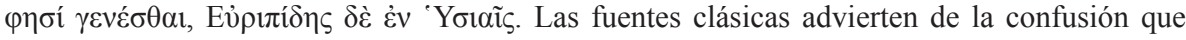
existía entre ambos topónimos y la posibilidad de que se refirieran a una misma localidad o a dos. Una lectura atenta de los testimonios sugiere dos emplazamientos diferentes, ambos en los confines entre Beocia y Ática: uno en la zona de Platea/Eritras, a los pies del Helicón en el curso alto del Asopo, y otro en la zona de Oenoe, cercana a Tanagra, Áulide y Oropo. Parece que en realidad Hyria e Hysiae son dos poblaciones diferentes con un mismo nombre en dos variantes sobre la base morfológica y dialectal: Hysiae debía ser la cercana a Platea (v. Hansen - Nilsen 2004, p. 443), donde se sitúa el nacimiento de Antíope (E., Fr. 180 Kannicht, cf. Str. IX 2.12; v. n. 7), mientras que Hyria tiene que ser la ciudad mencionada 
nacimiento de Orión según esta versión del mito, debía situarse, como hemos dicho, cerca de Tanagra, hacia el noreste, y del monte que separa el valle del Asopo de la costa de Áulide, que no puede ser el Monte Ptoion, sede del oráculo de Apolo Ptoios, situado más al norte. Tal vez el oráculo al que se refiere Corina estaba en Hiria. Hirieo sería, pues, héroe epónimo y sacerdote del oráculo, y posteriormente Orión le sucedió en tal dignidad. La persona loquens del poema de Corina sería, pues, un hijo de Orión (no necesariamente Acrefén, epónimo restituido y hapax legómenon), que habría heredado el oráculo después de la muerte y catasterismo de éste ${ }^{35}$. Corina, pues, habría bebido de fuentes locales vinculadas a la historia de un oráculo que pasó de manos de Evónimo a Hirieo, más tarde a Orión y finalmente al sacerdote que habla en primera persona en el poema. Cuatro vates se sucedieron, pues, en el trono profético ${ }^{36}$.

En definitiva, no parece en absoluto que Euforión de Calcis y posteriormente Ovidio, tributario del poeta helenístico, se hubieran inspirado en Corina. No es extraño, sin embargo, que en un ámbito tan restringido como es el de una comarca pequeña coexistieran versiones diversas sobre los mismos personajes del mito, como ya hemos apuntado ${ }^{37}$. El peculiar relato del nacimiento de Orión que nos transmite Euforión podría ser también una versión local que se remontaría a la prehistoria del mito y, a nuestro entender, y este es el principal objeto de nuestro análisis, a un mito vinculado a un ritual de fertilidad. Pasamos a continuación a exponer nuestra hipótesis.

La figura mítica de Hirieo está vinculada genealógicamente con las Pléyades y las Híades; además, con estas últimas comparte origen etimológico. En efecto, el doblete 'Ypía/'Yoíal, advertido por Estrabón (loc. cit.), puede ser debido a rotacismo, rasgo dialectal testimoniado en Oropo, donde se hablaba un dialecto de transición beocio/jónico, y en Eretria, en la costa de Eubea, al

en el Catálogo de las Naves homérico. También existen dos Oenoe, una cerca de Eritras, en Ática, y otra cerca de Tanagra y Oropo (v. Hdt. V 74, VI 108 y IX 15; Th. III 24). Estrabón da testimonio de la identificación de ambas ciudades, deshabitadas en su época. Pausanias se refiere sin duda a Hysiae, cerca de Platea y Eritras, ciudad en ruinas con vestigios de un templo de Apolo y un oráculo en un pozo.

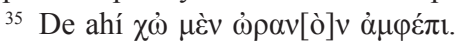

${ }^{36}$ El paralelismo que presenta esta relación con el relato de la sucesión de dioses poseedores del oráculo délfico en el prólogo de las Euménides de Esquilo nos sugiere la idea de que tanto el dramaturgo ateniense como la poetisa beocia recurren a un tópico literario.

${ }^{37}$ Parker 2011, p. 27; v. n. 16. 
otro lado del Euripo ${ }^{38}$. Este rasgo puede haber afectado por contigüidad a otras localidades del curso inferior del Asopo, donde presumiblemente se hallaba Hiria. En este caso la localización de Fossey debería descartarse.

La forma 'Yoía puede ser variante de 'Yó $\delta \varepsilon \varsigma^{39}$, «las que provocan la lluvia», de la misma raíz del verbo v̋ $\omega$, y nombre de las hermanas de las

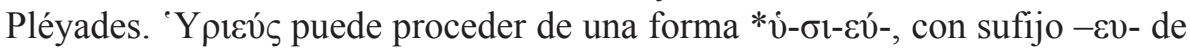
nombre propio que se correspondería con un adjetivo *ú-бı-. Así pues, el nombre de Hirieo, como el de la localidad Hiria, parecen tener la misma etimología que la del nombre de las Híades, relacionadas con la lluvia. Las Híades, hermanas de las Pléyades, son ninfas beocias catasterizadas y relacionadas etimológicamente, míticamente y quizás también en el ritual con la lluvia y, por extensión, con la fertilidad de los campos ${ }^{40}$. No es extraño, pues, que, en la versión analizada, Hirieo aparezca como un humilde campesino que tiene problemas de fertilidad. El estrecho vínculo en el mito y el rito griegos entre la fecundidad humana y la vegetal es bien conocido ya desde las tradiciones cosmogónicas y teogónicas, y no es ajeno al mito griego el motivo del dios que eyacula en el suelo, fertilizando la tierra y dando nacimiento a un hijo nacido de ella, un $\gamma \eta \gamma \varepsilon v \eta \varsigma^{41}$.

Hirieo es hijo de Posidón y una de las Pléyades, Alcíone, como relata Eratóstenes en sus Catasterismos ${ }^{42}$. También Corina, según veíamos, lo considera hijo de Posidón. De las Pléyades, tres se unieron a Zeus, dos a Posidón y una a Ares. El motivo genealógico ofrece la misma matriz narrativa que hemos observado anteriormente en Corina respecto a las hijas de Asopo: las seis hijas de Atlante y Pléyone ${ }^{43}$, ninfas beocias posteriormente astros, se unieron a tres dioses. En este punto no hay duda de que una parte de la tradición respecto a Hirieo es común: Hirieo era hijo de una ninfa, personifica-

${ }^{38}$ V. Buck 1955, p. 57; Bartoněk 1979, p. 124.

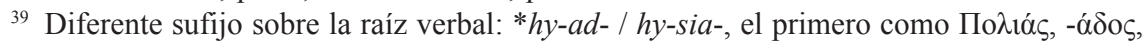

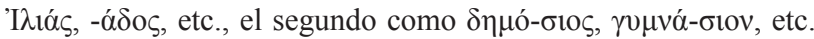

40 Pàmias 2004, pp. 132-133 n. 132.

${ }^{41}$ Cabe citar el caso de Erictonio (Apollod. III 14.5). V. Renaud 2004, pp. 161-162.

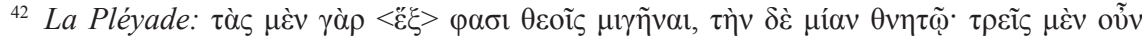

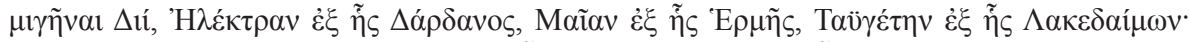

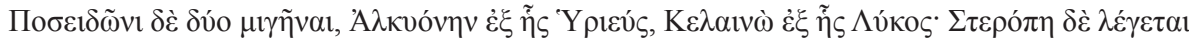

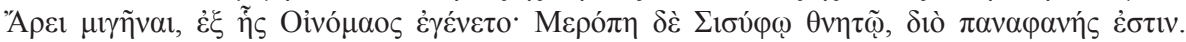
Véase el texto completo y comentario mitográfico y astrológico en Pàmias 2004, pp. 163-165.

${ }^{43}$ Para las diversas variantes del mito véase Hyg., Astr. 2.21; Excerptum de Pleiadibus Tzetzianum (Scholia in Aratum uetera, ed. J. Martin, pp. 547-551). 
ción de una fuente beocia hija de Atlante, el titán que sostiene el firmamento, y nieta de Océano, padre de todas las corrientes; su padre, Posidón, es precisamente el dios que en la mitología hace surgir las fuentes.

En la versión de Corina, Hirieo fue un profeta, mientras que en la de Euforión, un campesino. La variante quizás se deba al hecho de que Corina parece recoger una versión irradiada desde el oráculo mismo, con finalidades propagandísticas, mientras que Euforión bebe probablemente de fuentes orales asociadas al folclore. Es posible que Píndaro ya hubiera hecho alusión a dicha tradición, de ahí la noticia transmitida por Estrabón. El hecho de que Euforión bebiera de fuentes orales entraría en contradicción con su condición de poeta doctus y del carácter metaliterario de su poesía. No sería extraño, pues, que la fuente primera de Euforión hubiese sido Píndaro quien, a su vez, hubiese recogido una tradición popular beocia.

Hirieo se casó con la ninfa local Clonia. El nombre no aparece ni en el escolio ni en los Fasti, lo sabemos gracias al escoliasta de Licofrón ${ }^{44}$. Las tres fuentes coinciden en el motivo de la esterilidad del matrimonio ${ }^{45}$.

El relato mítico transmitido por Euforión y Ovidio se articula estructuralmente en torno a una concatenación de mitemas habituales ${ }^{46}$ que delatan un doble trasfondo ritual y folclórico. La hospitalidad de Hirieo para con los dioses revela un sustrato ritual de theoxeni ${ }^{47}$ : el humilde labrador les sirve legumbres que hierven en dos escudillas en el hogar. Al ofrecerles vino los huéspedes revelan su identidad: se produce en este punto la epifanía, que da lugar a una mayor obsequiosidad del anfitrión. En efecto, Hirieo sacrifica al único animal que tiene, su buey de labranza. Los tres dioses gozan de un completo banquete, con legumbres, carne y vino. La mesa en la que se sientan los tres dioses nos recuerda un altar colmado de ofrendas. La hospitalidad ha surtido efecto y los dioses se han manifestado. La theoxenía se ve premiada con la epifanía. La consiguiente concesión de un deseo como premio a su bondad y generosidad es otro de los motivos típicamente cuentísticos del relato bajo los cuales subyace este sustrato cultual al que venimos refiriéndonos ${ }^{48}$.

\footnotetext{
${ }^{44} \mathrm{~V}$. nota 20.

${ }^{45}$ Según Ovidio, enviudó y, como había jurado fidelidad perpetua a su esposa, no contrajo segundas nupcias, hecho que lo privaba de la paternidad por vía del matrimonio.

${ }^{46}$ V. Burkert 1979, pp. 67-70.

47 V. Ekroth 2002, pp. 136-140.

${ }^{48}$ Es el motivo de Filemón y Baucis (Ou., Met. VIII 616-715); v. Renaud 2004, pp. 173-180.
} 
A partir de este punto la narración adquiere un tono marcadamente mágico y ritualístico. Los tres dioses orinan (o quizás eyaculan ${ }^{49}$ ) en la piel del animal sacrificado y le ordenan a Hirieo que la entierre. Después del período de gestación deberá desenterrarla. Así fue como nació Orión según esta versión, en la cual, como hemos visto, el personaje es considerado un $\gamma \eta \gamma \varepsilon v \eta ́ s$,

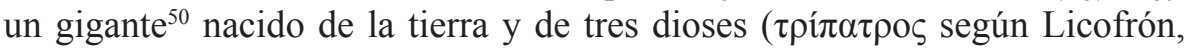
328).

El mito, como podemos observar, presenta una fusión de elementos de orígenes diversos. Dichos elementos le confieren una configuración narrativa sorprendente. Euforión, seguido por Ovidio, ha construido un relato mítico en que magia ${ }^{51}$, religión, mito y cuento se entretejen para evocar un pasado ya remoto para los dos autores.

El poeta helenístico, como ya hemos dicho, optó probablemente por una tradición popular de transmisión oral, que habría sido ya mencionada por Píndaro en uno de sus ditirambos, según leemos en Estrabón. Por eso, cuando Estrabón habla de la paternidad de Hirieo respecto a Orión, no cita a Euforión, a pesar de que debía conocer su obra, sino al poeta beocio, fuente anterior $\mathrm{y}$, en consecuencia, de más prestigio.

El interés por las versiones aberrantes puso en circulación estos mitos desconocidos fuera de sus ámbitos locales y penetró también en la literatura latina. Ovidio, en una obra de contenido folclorista y anticuario como los Fastos, la recupera. El alto grado de coincidencia en la trama narrativa y en los detalles del relato nos inclina a pensar que, efectivamente, el escolio a Homero resume la versión seguida por Euforión en un texto que sirvió de base hipotextual a Ovidio. Hemos de lamentar la imposibilidad de saber cuáles de estos elementos constitutivos se hallaban ya en Píndaro. Como mera hipótesis de trabajo, podemos inferir que, a partir de una mención pasajera al nacimiento de Orión en Beocia por parte de Píndaro, Euforión podría haber investigado las tradiciones en torno a este mito y podría haber reconstruido, con mayor o menor libertad, el relato, o incluso haber reelaborado el material hasta recrear un mito antiguo a partir de motivos preexistentes, pero que nunca antes se había dado como tal, al menos en la tradición escrita.

\footnotetext{
49 V. infra.

${ }^{50}$ Fontenrose 1981, pp. 5-32 lo consideraba un héroe.

51 V. Fowler 2000, passim, y especialmente pp. 318, 331-338.
} 
En el relato de Euforión/Ovidio el componente narrativo tiene un gran peso. El objetivo es crear una narración sorprendente con un alto poder de evocación de creencias, ritos y costumbres ancestrales. No hay en otras fuentes clásicas nada semejante en lo que a Orión se refiere. Es lógico si se tiene en cuenta la marginación de las variantes locales de los mitos debida al fenómeno del panhelenismo.

Podemos, sin embargo, recurrir a un texto hitita para encontrar algún paralelo sugerente, siempre teniendo en cuenta que corremos el riesgo de forzar en exceso la comparación y que el lapsus de tiempo entre el texto hitita y el de Euforión es de un milenio.

Existen varios textos hititas en los que se describe un ritual contra la impotencia masculina. Uno de ellos ${ }^{52}$ nos parece especialmente significativo y útil para esclarecer la antigüedad de los motivos narrativos asociados a rituales de magia y de fertilidad. Es el titulado Ritual contra la impotencia de Paškuwatti, del s. XIII a. C..$^{53}$, un texto hitita que recoge un rito luvita de la tierra de Arzawa. Arzawa ${ }^{54}$ es un topónimo luvita que designa la región central del occidente anatolio. En el s. XIII a. C. era un reino vasallo del imperio hitita y la población de Arzawa era mayoritariamente luvita ${ }^{55}$.

${ }^{52}$ KUB IX $27+$ KUB VII 8, García Trabazo 2002, pp. 447-465.

${ }^{53}$ Dicho texto comienza: «Así habla Paškuwatti, la mujer de Arzawa pero que está en Parašša». El topónimo Parašša es un hapax en hitita (y en luvita), por eso Hoffner (1987, p. 281) ha sugerido la emendatio Par-na-aš-ša, topónimo más frecuente en textos hititas y rela-

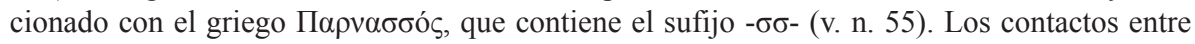
las dos riberas del Egeo en el segundo milenio están fuera de toda duda. Por consiguiente cabe postular un sustrato ritual en suelo beocio vinculado a ritos anatolios que se remontaría al segundo milenio.

${ }_{54}$ V. Heinhold-Krahmer 1977, Bryce 2006, pp. 77-86, David-Hawkins 2009, pp. 75-76.

${ }^{55}$ La toponimia anatolia o específicamente luvita en suelo griego ha sido puesta de manifiesto ya suficientemente. V. López Eire 1967 y, más recientemente, Finkelberg 2005, especialmente el capítulo 3 (pp. 42-64), donde recoge de manera sucinta las evidencias del sustrato anatolio indoeuropeo en suelo griego, basadas fundamentalmente en la toponimia y más concretamente en los topónimos y antropónimos con los sufijos $-v \theta-\mathrm{y}-\sigma \sigma$ - (ático $-\tau \tau$-). Véanse al respecto los mapas que facilita en las páginas 42-45. El sustrato prehelénico en suelo griego se revela sin duda anatolio. Es, pues, muy probable que la población «pelásgica» estuviese estrechamente emparentada con los pueblos indoeuropeos de Anatolia, especialmente los luvitas del segundo milenio. El parentesco lingüístico es indudable, y la praxis religiosa descrita en los textos hititas, así como algunos paralelismos en los mitos de cosmogonía no dejan lugar a dudas (v. g. el mito de Kumarbi en la teogonía hitita y el Canto de Ullikummi, v. Güterbock 1948). 
Los motivos que hemos aislado en nuestro análisis anterior del relato, a saber, theoxenía, epifanía, sacrificio, banquete y rito mágico de fertilidad, se reconocen también en este texto hitita. Ello nos sugiere un patrón ritual sobre el cual se fundamenta el mito y concretamente un rito como remedio contra la falta de descendencia cuyo sujeto es el varón, incapaz de engendrar un hijo. Pasemos a analizarlos de manera más pormenorizada ${ }^{56}$.

El relato beocio que hemos estudiado está constituido, como ya hemos visto, sobre el patrón mítico-narrativo de la theoxenía u hospitalidad dispensada a los dioses. En el texto hitita, entre las instrucciones que la sacerdotisa da al destinatario del texto, el hombre que sufre de impotencia, figura esta theoxenía, que en este caso no es un motivo narrativo sino una parte del rito que hay que practicar ( $K U B$ VII $5+K U B$ IX 27 recto I, líneas 46-4957):

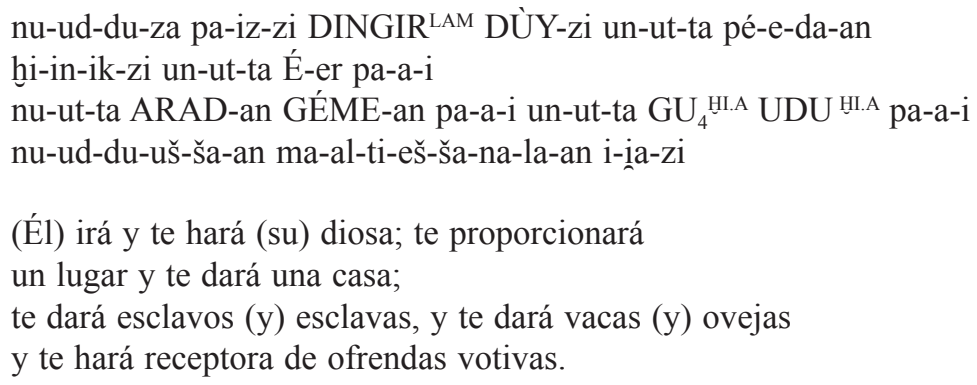

Y un poco más adelante leemos (KUB VII 5 recto II, líneas 5'-8'):

nu SÍSKUR ku-e-da-ni pár-ni iš-ša-ah-ḩi

nu GIŠBANŠUR GIBIL ki-it-ta-ri

nu-u š-ša-an NINDA.ÉRINMEš še-er $I-N A$ GIŠBANŠUR te-e

h-hi pí-ra-an kat-ta-ma ${ }^{\text {DUG }} K U-B U-U B$ te-eh-hgi

${ }^{56}$ Renuncio aquí a analizar la posible, incluso probable, relación del mito de Asopo con tradiciones anatolias, ya que tal discusión quizás merezca un estudio sistemático en un futuro artículo. En efecto, el mito de Asopo, tal como se narra en el escolio D a Il. I 180 (van Thiel) es un ejemplo del uso del patrón narrativo del dios que desaparece provocando hambruna entre los hombres, como el dios hático Telipinu y la diosa griega Deméter (v. Kirk 1982, p. 206, Burkert 1979, p. 140; Bernabé, 1979, p. 39-45; García Trabazo 2002, p. 108-109), un nuevo dato para demostrar los vínculos de Beocia con la Anatolia Occidental (Arzawa en los documentos hititas); es inevitable pensar aquí en el origen minorasiático de Hesíodo, cuyo padre regresó a Beocia desde la colonia eolia de Cumas.

${ }^{57}$ La edición y traducción es la de García Trabazo 2002, pp. 447-465. 
En la casa en la que realizo el ritual, se instala una nueva mesa, y pongo el pan de soldado encima, en la mesa; delante de ésta deposito una jarra.

El oferente, afectado de impotencia, invoca, mediante una sacerdotisa, Paškuwatti $^{58}$, a la diosa agraria Uliliyašši ${ }^{59}$, y le ofrece hospitalidad en su casa, donde se pone una «nueva» mesa con ofrendas alimenticias. El ritual dura tres días, durante los cuales el oferente ofrece tres ágapes a la diosa y le reza ante la mesa de ofrendas. También sacrifica una oveja, la trocea y la sirve en el banquete (KUB VII 5 recto II 20'-30' + verso III 1-12):

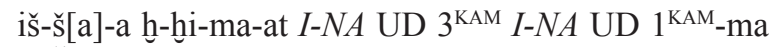

3- $\breve{S} U$ mu-u-ga-mi ka-ru-ú-ư⿱a-ri- u্রa-ar

UD-KAM!-ti iš-tar-na pé-di 1-ŠU ne-ku-uz me-hur

1-[Š $] U$ me-mi-ỉa-un-ša-kan an-da a-pu-u-uš-pát

me-mi-iš-ki-mi NINDA.GUR ${ }_{4} \cdot$ RA $^{\text {HI.A- }}{ }_{-i a}$

ku-i-uš ka-ru-ú-ư⿱a-ri- u्रa-ar

pár-ši-ia-an-na-a h-hi iš-tar-na UD-KAM!-ti-ma

NINDA.GUR 4 .RA da-ma-uš pár-ši-ia-an-na-a h-hii

ne-ku-uz me-ḩur-ra da-ma-uš pár-ši-ia-an-na-a h-hi

me-ma-al-la-aš-ša da-ma-a-i

iš-ḩu-u-una-an-na-ah-hi

nam-ma-kán 1 UDU $A$ - $N A$ DÚ-li-li-ia-aš-ši

ši-ip-pa-an-ta h-hi na-an GIŠBANŠUR-i

[p]í-ra-an kat-ta hu-u-kan-zi

[n]a-[aš-ta] UDU pa-ra-a pé-e-da-an-zi

[na-an-ha-at-t]a-an-zi nam-ma-an-kán

[mar-kan-zi(?)] na-aš-ta ${ }^{\text {UZU šu-up-pa }}$

[ ]x ${ }^{\text {UZU GABA }}{ }^{\text {UZUZAG.UDU }}$

[ ]-at $A$-NA GišBANŠUR

[kat-ta-an ar-ha t]i-an-zi UzUNÍG.GIG

[ ]x za[-un-un]a-an-zi

[ ]x 2 NINDA.GUR 4 .RA ${ }^{\text {HI.A }}$

[ ]x-ši-kán $A$-NA GIŠBANŠUR

${ }^{58}$ Paškuwatti describe sin duda un rito de purificación. Disponemos de un ejemplo de rito de purificación contra la impotencia en Hiponacte de Éfeso, fr. 92 Rodríguez Adrados. Véase al respecto Parker 1983, p. 208 y nota 6.

${ }_{59}$ Sobre estos dos personajes v. Hutter 2003, pp. 237-238. 
Haré esto durante tres días: cada día

rezaré tres veces, (una) por la mañana,

otra vez al mediodía (y) ot[ra] vez por la noche,

y mientras tanto iré diciendo

estas mismas palabras. Y las hogazas,

unas (las) estaré partiendo

por la mañana, al mediodía

estaré partiendo otras hogazas,

y por la noche estaré partiendo otras.

También estaré esparciendo otra (porción) de sémola.

Y además sacrificaré una oveja

a Uliliyašši, y la matarán abajo,

[d]elante de la mesa;

se llevarán la oveja,

[la cort]arán, (y) luego la

[trincharán]. De la carne

[...] ... el pecho (y) la espaldilla

$[\ldots y]$ los [po]ndrán [abajo, delante]

de la mesa. El hígado

[y el corazón (los)] co[cin]arán.

[...] ... dos hogazas

[ ...las $][\ldots]$ para él en la mesa.

La diosa deberá hacer acto de presencia, es decir, manifestarse en epifanía. Para conseguirlo el oferente debe dormir en la casa y esperar que la diosa se le aparezca en sueños y se acueste con él.

Mientras duerme deberá extender sus vestidos y su capa. De no hacerlo, la diosa no se aparecerá. Esta práctica nos da a pensar en la acción de enterrar la piel del animal sacrificado en el mito beocio de Hirieo. A pesar de que este motivo literario no coincida literalmente con el procedimiento ritual descrito en el texto hitita, no cabe duda de su similitud y, lo que es más significativo, la coincidencia en la finalidad de ambos actos: obtener descendencia. Vemos como dos motivos narrativos similares coinciden en cuanto a su función ritual. En el ritual que describe la sacerdotisa Paškuwatti se suceden, pues, theoxenía, sacrificio, rito mágico y ulterior epifanía ${ }^{60}$. La misma sucesión de

${ }^{60}$ Esta última, por supuesto, no tiene lugar, pero es el objetivo del ritual. La consecución de la epifanía es condición sine qua non para que el ritual surta efecto y los deseos del oferente se vean cumplidos. 
motivos la hallamos en la historia de Hirieo: ofrece hospitalidad a los dioses, les sirve diversos alimentos en la mesa, sacrifica un buey y al final los dioses se manifiestan en epifanía y cumplen su deseo.

Regresemos al relato de Ovidio y su hipotexto euforioneo. En ambos se describe un rito mágico, a saber, el entierro de una piel de buey mojada con la orina de los dioses, para que el oferente obtenga descendencia. La descripción del rito constituye el núcleo narrativo del relato, y se llega a éste tras la secuencia theoxenía, sacrificio, banquete y epifanía. La pauta ritual subyace sin duda a la estructura narrativa del mito. El patrón en sí no tiene nada de sorprendente, en tanto en cuanto constituye un procedimiento habitual de las religiones antiguas. Sin embargo, dado que nos hallamos ante un rito muy concreto con una finalidad específica, debemos atender a la coincidencia de dos detalles para postular una relación más estrecha entre ambos textos. Éstos son, en primer lugar, el significado que tiene la piel del buey sacrificado con el elemento análogo en el texto hitita, que es «los vestidos y la capa» del oferente. En segundo lugar, el significado que tiene la orina en el rito. Es obvio que no existe una relación directa entre ambos textos, pero sí parece darse entre dos tradiciones ancestrales de carácter ritual.

En cuanto a la piel del buey, Hirieo la entierra siguiendo las indicaciones de los dioses y de ella obtendrá descendencia. En el texto hitita la sacerdotisa le dice al oferente que deberá «poner abajo» (i. e., en el suelo) los vestidos y la capa que previamente se habían depositado encima de la mesa de ofrendas, sobre el «pan de soldado» (sic). Sin duda nos hallamos ante un rito de contacto y transmisión ${ }^{61}$ en virtud del cual la impureza que afecta al oferente, causa de su impotencia, pasa a sus vestidos, y de éstos a la tierra, símbolo de fecundidad y divinidad primigenia, la cual purificará dicha impureza y permitirá que el siguiente paso del ritual surta efecto: la epifanía por incubación, mediante la cual la diosa Uliliyašši restituirá la capacidad reproductora del oferente.

No cabe duda de que, análogamente a lo descrito en el texto hitita, el animal sacrificado en el relato beocio, el buey, expía la falta de descendencia de Hirieo, y su piel enterrada, que cumple la misma función que «los vestidos y la capa» del oferente del texto hitita, le dará el fruto deseado.

Es importante sin embargo no olvidar que el mito de Hirieo no es la descripción de un ritual. Euforión y, posteriormente, Ovidio relatan una tradición

61 Para los llamados Kontaktriten y Übertragungsriten en la religión hitita véase Haas 1994, pp. 893-895, 898-899. 
local en la cual el sustrato ritual es sólo un eco lejano. El interés, tanto del poeta como del lector, se centra en el relato en sí, en su rareza y en su dimensión folclórica y anticuaria, ya muy alejada de su origen ritual.

El segundo aspecto al que concedemos una significación especial es el de la orina. ¿Por qué los dioses orinan en la piel? ¿No sería más «lógico» (al menos desde nuestro punto de vista, más racional) que eyaculasen ${ }^{62}$ En el texto hitita se hace referencia a la orina del oferente, a quien se le llama «el hijo de la inconstancia, del excremento y la orina» refiriéndose a su incapacidad de mantener contacto sexual. Aquí las dificultades de interpretación nos obligan a ser aún más cautos. Podemos, como mínimo, poner de manifiesto el hecho de que en un texto que describe un ritual contra la incapacidad de engendrar de un hombre se mencione la orina. ¿Puede ser ésta también un vehículo para la eliminación de la impureza, como lo son los vestidos depositados en el suelo? Desde un punto de vista simbólico tiene sentido. Sin embargo ello plantea un problema: en el mito beocio son los dioses los que orinan, cuando sería más lógico que hubiese sido el propio Hirieo. La tradición puede haber provocado alguna alteración al respecto, y no osamos aventurar una explicación, que sería meramente especulativa ${ }^{63}$. Es relevante, sin embargo, el hecho de que el mito beocio del nacimiento de Orión otorgue un valor especial a la triple paternidad divina, relegando el papel de Hirieo al de simple padre putativo. No podemos saber si en origen era Hirieo quien orinaba sobre la piel, hecho que estaría más de acuerdo con el sustrato ritual que estamos intentando poner de manifiesto. Sin duda el nombre mismo de Hirieo, en beocio Ov́pıvús, debe haber incidido en la atribución de una tradición popular sobre un campesino que es padre gracias a un ritual curativo en el que la orina tiene una participación determinante. La similitud de la raíz

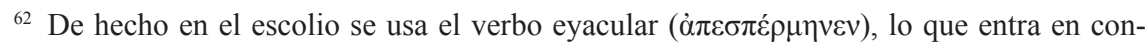
tradicción con la paretimología del nombre de Orión. Parece que en el texto se ha sustituido un verbo por otro por una mera racionalización. Indicio de ello es la versión del escoliasta de

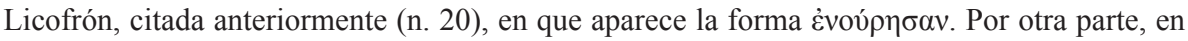
griego el verbo oủ $\varepsilon ́ \omega$ no aparece con el sentido traslaticio de «eyacular» hasta época muy tardía; cf. Ant. Lib. 41.4.

63 Scheidweiler propuso una enmienda del texto del escolio substituyendo ov̉ $\tilde{\eta} \sigma \alpha 1$ ஸ̆ $\sigma \pi \varepsilon \rho$

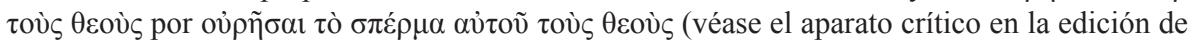
Clua). Admitiendo dicha conjetura se entendería que los tres dioses derramaron el semen de Hirieo sobre la piel del buey, y el sentido ritual del mito sería más claro, ya que la paternidad de Hirieo sería literal. Pero la corrección es excesiva desde el punto de vista paleográfico y textual. 
del nombre pronunciado en beocio ${ }^{64}$ con la del verbo que significa orinar en griego, oủ $\rho \tilde{i} v$, habría propiciado la paretimología. De esta manera, Hirieo se habría convertido en el protagonista de una antigua tradición oral, aprovechando la (falsa) etimología como mecanismo fabulador ${ }^{65}$.

Euforión y Ovidio no vinculan oủpeĩv con Hirieo sino con Orión, sin duda herederos de una versión que alteraba el estado originario y que ponía el acento en el gigante catasterizado, personaje de gran relevancia en la tradición panhelénica, cosa que no puede decirse de Hirieo, por su dimensión meramente local. El nombre de Orión es sin duda más distante del verbo ov̉peĩv por lo que respecta a la fonética, sobre todo teniendo en cuenta que en beocio el nombre documentado es una forma no contracta ' $\Omega \alpha \rho^{\prime} \omega v^{66}$.

Sea como fuere, y a pesar de las dificultades de interpretación, la mención de la orina en dos textos que ya presentan la serie de coincidencias que hemos analizado apunta hacia ese sustrato ritual compartido al que venimos refiriéndonos, que demuestra que los relatos de Euforión y Ovidio conservan rasgos muy antiguos del rito y la magia que se remontan sin duda al segundo milenio, al bronce tardío, época en la que griegos y anatolios compartían creencias y prácticas.

Es hora ya de finalizar este análisis exponiendo las conclusiones fundamentales de nuestro estudio.

En primer lugar, Euforión y, posteriormente Ovidio, relatan un mito epicórico con un interés meramente literario, de acuerdo con sus finalidades y su programa poético ${ }^{67}$. El poeta helenístico recupera una tradición marginal y marginada por el panhelenismo imperante en épocas arcaica y clásica, le confiere una estructura narrativa coherente y la pone de nuevo en circulación. Dicha tradición era conocida también por Licofrón y, muy probablemente, también por Píndaro.

El texto de Euforión no se nos ha conservado, pero sí un resumen en un escolio a la Ilíada. Si partimos de las características de la poesía de Euforión y en concreto del uso particular que el poeta hace del mito, llegamos a la conclusión de que probablemente Euforión no explicaba el mito en su totali-

\footnotetext{
${ }^{64}$ Probablemente con psilosis [ūr-] en la lengua coloquial a partir del s. IV a.C.

${ }^{65}$ V. Tsitsibakou -Vasalos 2007, pp. 57-59, donde se analiza la función de la etimología como factor narrativo en la épica.

${ }^{66}$ V. Fontenrose 1981, p. 25, n. 3.

${ }^{67}$ En cuanto a la poesía y la poética de Euforión, v. Clúa 1992, pp. 9-18; Kolde 2006 y 2013.
} 
dad; quizás solamente aludía a él o lo relataba parcialmente, y era el lector cultivado de su época el que debería suplir las omisiones ${ }^{68}$. Euforión, y la poesía helenística en su conjunto, se caracteriza por la manera como interpela al lector y le plantea un reto intelectual. La literatura exegética y, concretamente en este caso, los escolios mitográficos eran obras de consulta al uso de lectores ávidos de erudición e interesados en tradiciones excéntricas. El análisis del pasaje y el escolio de Licofrón que hemos citado anteriormente son un buen ejemplo de ello ${ }^{69}$.

Ovidio, por su parte, retoma el mito y lo introduce en sus Fasti invitando al lector a una lectura también erudita. Su relato es completo, a excepción de la aposiopesis del verso 532, que sugiere el conocimiento del mito por parte del lector instruido, con una referencia irónica al pudor que le impide describir el acto de la micción de los dioses sobre la piel, y que deja en suspense al lector desconocedor del mito (vv. 531-532): adnuerant omnes. Omnes ad terga iuuenci / constiterant - pudor est ulteriora loqui.

La comparación que hemos establecido con el texto hitita debe ser entendida teniendo en cuenta la enorme distancia histórica e ideológica: el Ritual contra la impotencia de Paškuwatti no es un texto literario dirigido a lectores eruditos, algo inconcebible en la Anatolia del Bronce, sino la descripción pormenorizada de un procedimiento ritual. El nexo entre ambos textos es remoto. El sentido de la comparación que hemos llevado a cabo como método para nuestro análisis yace en la coincidencia de una serie concreta de motivos, especificados supra, que nos hacen pensar en un sustrato ritual muy concreto subyacente al mito beocio. La existencia de dicho sustrato demostraría que el relato de Euforión (y Ovidio) no es un simple pastiche decadente, sino el resultado de una investigación anticuaria sobre tradiciones locales, en este caso concreto, sobre el mito beocio de Hirieo. Cada uno de los mitemas $^{70}$ constituyentes del relato tiene su eco en un rito antiguo, y la concatenación de dichos ritos coincide en gran parte con el procedimiento ritual descrito en el texto hitita.

Los poetas helenísticos manifestaron un interés especial por las versiones olvidadas y sorprendentes del mito. Euforión fue discípulo de Calímaco, el

${ }^{68}$ V. Kolde 2006, p. 162.

${ }^{69}$ V. n. 20, 21.

${ }^{70}$ Respecto a este enfoque estructuralista relacionado con el método comparativo, véase Burkert 1987, especialmente pp. 11-12. 
poeta anticuario autor de los Aetia, siempre a la búsqueda de la discrepancia, la rareza y la marginalidad. No cabe duda, pues, de que el poeta de Calcis, en el texto en que trataba este mito, nos ofrecía detalles de una versión beocia diferente de la tradición recogida por Corina, estrechamente vinculada a un oráculo beocio de Apolo, que no parece haber sido el de Apolo Ptoios en Acrefia sino otro localizado en la localidad de Hiria, deshabitada en época de Estrabón y olvidada en tiempos de Pausanias, pero ya citada por Homero en el Catálogo de las Naves.

\section{BIBLIOGRAFÍA}

Bartoněk, A. 1979: «Greek Dialects between 1000 and 300 BC», Studi Micenei ed Egeo-Anatolici 20, pp. 113-130.

Bernabé, A. 1979: Textos literarios hititas, Madrid.

Bowra, C. M. 1938: «The Daughters of Asopus», Hermes 73, pp. 213-221.

Bryce, T. 2006: The Trojans and their Neighbours, Londres - Nueva York.

Buck, C. D. $1968^{4}$ (1955): The Greek Dialects. Grammar, Selected Inscriptions, Glossary, Chicago - Londres.

Burkert, W. 1979: Structure and History in Greek Mythology and Ritual, Berkeley.

Burkert, W. 1987: «Oriental and Greek Mythology: The Meeting of Parallels», en Bremmer, J. (ed.), Interpretations of Greek Mythology, Londres, pp. 10-40.

Cameron, A. 2004: Greek Mythography in the Roman World, Oxford.

Clayman, D. 1883: «Corinna and Pindar», en Rosen, R. M. y Farrell, J. (eds.), Nomodeiktes. Greek Studies in Honor of Martin Oswald, Ann Arbor, pp. 633-642.

Clua, J. A. 1992: Euforió de Calcis. Poemes i fragments, Barcelona.

Collins, D. 2006: «Corinna and Mythological Innovation», Classical Quarterly 56.1, 19-32.

Cuartero, F. J. 2012: Pseudo-Apol·lodor, Biblioteca, vol. I, Introducció, edició crítica, traducció i notes, Barcelona.

David-Hawkins, J. 2009: «The Arzawa Letters in Recent Perspective», British Museum Studies in Ancient Egypt and Sudan 14, pp. 73-83.

Ekroth, G. 2002: The Sacrificial Rituals of Greek Hero Cults in the Archaic to the Early Hellenistic Periods, Kernos, supl. 2, Lieja.

Finkelberg, M. 2005: Greeks and Pre-Greeks. Aegean Prehistory and Greek Heroic Tradition, Cambridge.

Fontenrose, J. 1981: Orion: The Myth of the Hunter and the Huntress, Berkeley Los Ángeles - Londres.

Fossey, J. M. 1988: Topography and Population of Ancient Boeotia, Chicago. 
Fowler, R. 2000: «Greek Magic, Greek Religion», en Buxton, R. (ed.), Oxford Readings in Greek Religion, Oxford, pp. 317-343.

Frazer, J. G. 1898: Pausanias' description of Greece, translation with a commentary, vol. V, Londres.

Funke, P. 2013: «Hyria», Brill's New Pauly. Brill Online, <http://referenceworks. brillonline.com/entries/brill-s-new-pauly/hyria-e520240> (17/05/2013).

García Trabazo, J. V. (ed.) 2002: Textos religiosos hititas, Madrid.

Gentili, B. 2003: «Le Asopidi. Corinna, PMG 694 col. 3 12-51», en Basson, A. F. y Dominik, W. J. (eds.), Literature, Art, History: Studies on Classical Antiquity and Tradition in Honour of W. J. Henderson, Fráncfort del Meno, pp. 211-223.

Guillon, P. 1958: «Corinne et les oracles béotiens: la consultation d'Asopos», Bulletin de Correspondance Hellénique 82, pp. 47-60.

Güterbock H. G. 1948: «The Hittite Version of the Hurrian Kumarbi Myth: Oriental Forerunners of Hesiod», American Journal of Archaeology, 52.1, pp. 123-34.

Haas, V. 1994: Geschichte der Hethitischen Religion, Leiden, Nueva York y Colonia.

Hansen, M. H., y Nielsen, T. H. (eds.) 2004: An Inventory of Archaic and Classical Poleis, Oxford.

Heinhold-Krahmer, S. 1977: Arzawa. Untersuchungen zu seiner Geschichte nach den hethitischen Quellen, Heidelberg.

Higbie, C. 2007: «Hellenistic Mythographers», en Woodard, R. D. (ed.), The Cambridge Companion to Greek Mythology, Cambridge, pp. 237-254.

Hutter, M. 2003: «Aspects of Luwian Religion», en Craig Melchert, H. (ed.), The Luwians, Handbook of Oriental Studies 68, Boston, pp. 211-280.

Kirk, G. S. 1982: El mito: su significado y funciones en la Antigüedad y otras culturas, Barcelona (original en inglés 1970).

Kolde, A. 2006: «Euphorion de Chalcis, poète hellénistique», en Harder, M. A., Regtuit, R. F. y Wakker, G. C. (eds.), Beyond the canon, Hellenistica Groningana 11, Leuven - Dudley, MA, pp. 141-166.

Kolde, A. 2013: «Les chevaux d'Asbotos et les génisses des Téléboens: les fragments du Thrace comme échantillons de la poétique d'Euphorion», en Cusset, C., Prioux, E., Richer, H. (eds.), Euphorion et les Mythes: images et fragments, Nápoles, pp. 281-298.

Larson, J. 2001: Greek Nymphs. Myth, Cult, Lore, Oxford.

Larson, J. 2002: «Corinna and the daughters of Asopus», Syllecta Classica 13, pp. 47-62.

López Eire, A. 1967: «Los topónimos en -ssos y -nthos y el Indoeuropeo», Zephyrus 18, pp. 129-135.

Massa-Pairault, F. H. 2013: «Orion», en Cusset, C., Prioux, E. y Richer, H. (eds.), Euphorion et les Mythes: images et fragments, Nápoles, pp. 41-61.

Ortolá-Guixot, A. 2005: «Corina y su poesía: una revisión», Minerva 18, pp. 71-91. Page, D. L. 1953: Corinna, Londres. 
Pagès Cebrián, J. 2013: «Euphorion dans les scholies mythographiques à l'Iliade», en Cusset, C., Prioux, E., Richer, H. (eds.), Euphorion et les Mythes: images et fragments, Nápoles, pp. 247-264.

Palumbo-Stracca, B. M. 1993: «Corinna e il suo pubblico», en Pretagostini, R. (ed.), Tradizione e innovazione nella cultura greca da Omero all'età ellenistica. Scritti in onore di Bruno Gentili II, Roma, pp. 402-412.

Pàmias, J. 2004: Eratòstenes, Catasterismes. Introducció, edició crítica, traducció i notes, Barcelona.

Parker, R. 1983: Miasma. Pollution and Purification in Early Greek Religion. Oxford [Reimpresión 2003].

Parker, R. 2011: On Greek Religion, Ithaca - Londres.

$P M G=$ Poetae Melici Graeci, ed. D. L. Page, Oxford, 1962.

Renaud, J. M. 2004: Le Mythe d'Orion, Lieja.

Thomas, R. 1992: Literacy and Orality in Ancient Greece, Cambridge.

Tsitsibakou-Vasalos, E. 2007: Ancient Poetic Etymology. The Pelopids: Fathers and Sons, Stuttgart.

Van Rossum-Steenbeek, M. 1998: Greek Reader's Digests? Studies on a Selection of Greek Subliterary Papyri, Leiden, Nueva York y Colonia. 